\title{
Collaboration Patterns as a Function of Article Genre among Mixed Researchers: A Mixed Methods Bibliometric Study
}

\author{
John Jordan \\ Department of Educational Leadership and Counseling, Sam Houston State University
} Box 2119, Huntsville, Texas 77341-2119, USA

Melanie Wachsmann

Department of Educational Leadership and Counseling, Sam Houston State University Box 2119, Huntsville, Texas 77341-2119, USA

\section{Susan Hoisington}

Department of Educational Leadership and Counseling, Sam Houston State University Box 2119, Huntsville, Texas 77341-2119, USA

\section{Vanessa Gonzalez}

Department of Educational Leadership and Counseling, Sam Houston State University Box 2119, Huntsville, Texas 77341-2119, USA

\section{Rachel Valle}

Department of Educational Leadership and Counseling, Sam Houston State University Box 2119, Huntsville, Texas 77341-2119, USA

Jarod Lambert

Department of Educational Leadership and Counseling, Sam Houston State University Box 2119, Huntsville, Texas 77341-2119, USA 


\title{
Majed Aleisa
}

Department of Educational Leadership and Counseling, Sam Houston State University

Box 2119, Huntsville, Texas 77341-2119, USA

\section{Rachael Wilcox}

Department of Educational Leadership and Counseling, Sam Houston State University

Box 2119, Huntsville, Texas 77341-2119, USA

\section{Cindy L. Benge}

Department of Educational Leadership and Counseling, Sam Houston State University

Box 2119, Huntsville, Texas 77341-2119, USA

Anthony J. Onwuegbuzie (Corresponding author)

Department of Educational Leadership and Counseling, Sam Houston State University

Box 2119, Huntsville, Texas 77341-2119, USA

$\&$

Distinguished Visiting Professor, Faculty of Education, University of Johannesburg

B-Ring 433, Kingsway Campus, Auckland Park, South Africa

E-mail: tonyonwuegbuzie@aol.com

Received: February 7, 2017 Accepted: April 2, 2017 Published: April 5, 2017

doi:10.5296/jei.v3i1.10699 URL: http://dx.doi.org/10.5296/jei.v3i1.10699

\begin{abstract}
Surprisingly, scant information exists regarding the collaboration patterns of mixed methods researchers. Thus, the purpose of this mixed methods bibliometric study was to examine (a) the distribution of the number of co-authors in articles published in the flagship mixed methods research journal (i.e., Journal of Mixed Methods Research [JMMR]) as a function of article genre (Quantitative Phase); (b) the relationship between the genre of articles published in JMMR and degree of collaboration in these articles (Quantitative Phase); (c) the difference between the number of authors in empirical research articles and non-empirical research
\end{abstract}


articles published in JMMR (Quantitative Phase); and (d) select leading mixed methods researchers' collaboration experiences as a function of genre of article (Qualitative Phase). An analysis of all articles published in JMMR from 2007 (its inception) to 2015 (the latest complete year at the time that the study was conducted) revealed (a) a statistically significantly higher proportion of empirical research articles $(63.2 \%)$ than non-empirical research articles $(36.8 \%)$, (b) that empirical research articles were 1.4 times $(95 \%$ confidence interval $=1.10,1.78$ ) more likely to involve multiple authors than were non-empirical research articles; and (c) that empirical research articles contained statistically significantly more authors than did non-empirical research articles. With respect to the qualitative phase, four themes (i.e., mental perception, mixed methods research, publication and research aids, and independent/group work) emerged regarding collaboration for empirical articles versus for non-empirical research articles. Implications of these findings are discussed.

Keywords: Mixed methods bibliometric study, Collaboration patterns, Genre of article, Empirical research articles, Non-empirical research articles, Theoretical articles, Methodological articles, Conceptual articles

\section{Introduction}

In general, works published in journals fall under two broad categories: empirical research articles and non-empirical research articles. Specifically, as noted by Onwuegbuzie and Frels (2016), empirical research articles

represent research wherein data are generated via direct observation or experiment in order to address one or more research questions (i.e., interrogative statements that the researcher attempts to answer using research techniques) and/or to test one or more hypotheses (i.e., proposed explanations of observable phenomenon that can be tested via research). As such, findings from empirical research studies are based on actual evidence, as opposed to theory, assumptions, or speculations. (p. 4)

Moreover, an empirical research article involves the primary reporting of the conduct of a study in which quantitative and/or qualitative data are collected and analyzed quantitatively and/or qualitatively. Thus, an empirical research article involves the reporting of a quantitative research study (i.e., comprising the collection, analysis, legitimation, and interpretation of numeric data, with objectives that include: to explore, to describe, to explain, to control, and to predict phenomena), a qualitative research study (i.e., comprising the collection, analysis, legitimation, and interpretation of nonnumeric data that naturally occur from one or more of the following sources: documents, talk, observations, and images), or a mixed methods research study (i.e., involving the mixing or combining of "quantitative and qualitative research techniques, methods, approaches, concepts or language ... [within] a single study"; Johnson \& Onwuegbuzie, 2004, p. 17). All three types of studies (i.e., quantitative research study, qualitative research study, mixed methods research study) optimally involve the following four phases: research conceptualization (e.g., determining the goal, objective, rationale, and purpose of the study; developing the research question[s]), research planning (i.e., selecting the sampling design and research design), research implementation (i.e., collecting, analyzing, legitimizing, and interpreting data), and research 
dissemination (i.e., sharing the research findings [e.g., orally, visually, in writing]).

In stark contrast, non-empirical research articles represent works that do not involve the primary reporting of the conduct of a study. Rather, these articles can be conceptual, theoretical, methodological, or historical in nature. Conceptual articles involve the introduction of a new or expansion of an existing concept, idea, thought, interpretation, concern, challenge, schema, or the like. Theoretical articles involve the introduction, modification, or expansion of one or more theories or models that optimally stem from concepts, assumptions, ideas, beliefs, propositions, hypotheses, hunches, findings, or the like. Methodological articles involve the introduction of a new or expansion of an existing research design or method (e.g., sampling design, instrumentation, procedures, analysis). Finally, historical articles involve the author(s) situating the extant literature in historical contexts such that they yield a historical framing of a phenomenon, concept, event, experience, or other entity. Simply put, for the most part, non-empirical research articles in general, and conceptual, theoretical, methodological, or historical articles in particular, should represent persuasive essays wherein these articles contain "a warranted and transparent path of argumentation in which parts are integrated to form a logical and coherent whole that exceeds the sum of its parts and wherein conclusions are logically based on appropriate evaluative frameworks" (Onwuegbuzie \& Frels, 2016, p. 363).

Whereas empirical research articles are overwhelmingly characterized by Introduction/Literature Review, Method, Results, and Discussion sections, non-empirical research articles do not have these components. Instead, non-empirical research articles are not so formulaic, and, hence, (potentially) are substantially more diverse. And this gap in diversity is even more profound for mixed methods research articles because non-empirical mixed methods research articles can be quantitatively focused (e.g., involving a new procedure or analysis for the quantitative phase[s] of mixed methods research studies), qualitatively focused (e.g., involving a new procedure or analysis for the qualitative phase[s] of mixed methods research studies), or mixed methods focused (e.g., involving a new procedure or analysis for the quantitative and qualitative phases of mixed methods research studies). As such, it could be argued that these two categories of research articles (i.e., empirical research articles, non-empirical research articles) require a different set of scholarship skills - especially with respect to the field of mixed methods research. And it is likely that this different set of scholarship skills, thought processes, and formats necessitates different levels and types of collaboration among authors representing these two categories of research articles. Yet, to date, collaboration patterns as a function of genre very rarely has been the focus of investigation. One notable exception is the bibliometric study (i.e., study of the academic literature using techniques such as a citation analysis) conducted by Fisher, Cobane, Ven, and Cullen (1998), which led to the finding that multiple authorship was more common for empirical research articles wherein sophisticated quantitative research approaches were used. Notwithstanding, to date, we could not find a single study in which the degree of collaboration rates was compared as a function of genre (i.e., empirical articles vs. non-empirical articles) of mixed methods research articles. Further, none of these numerous bibliometric studies included the use of qualitative research approaches. Yet, information 
about collaboration patterns would be useful for beginning and emergent mixed methods researchers as they learn how effectively to write these two categories of articles. Thus, this was the focus of the present mixed methods research article. Specifically, using Plano Clark and Badiee's (2010) typology, the research questions in this study represented separate research questions - specifically two quantitative research questions coupled with one qualitative research question. The following quantitative research questions were addressed:

1) What is the distribution of articles published in a select mixed methods research journal as a function of genre?

2) What is the relationship between the genre of articles published in a select mixed methods research journal and degree of collaboration in these articles?

3) What is the difference between the number of authors in empirical research articles published in a select mixed methods research journal and the number of authors in non-empirical research articles published in the same select mixed methods research journal?

The following qualitative research question was addressed:

4) What are select leading mixed methods researchers' collaboration experiences as a function of genre of article?

\subsection{Genre of Articles Published in Mixed Methods Research}

Journal of Mixed Methods Research (JMMR) is the flagship journal for mixed methods researchers. According to the JMMR submission guidelines-and supporting our earlier contention regarding two broad genres of articles- "JMMR publishes two types of manuscripts: empirical research and methodological/theoretical discussions" (Fetters \& Freshwater, 2015, p. 205). Fetters and Freshwater (2015) state that for methodological/ theoretical discussions,

Topics of interest include the following: types of research/evaluation questions, designs, sampling or measurement procedures, approaches to data analysis and integration, validity, software applications, paradigmatic stance, writing structure, theoretical lenses, cultural issues, ethical issues, validity, and quality issues in mixed methods research. The hourglass model for such papers generally should follow that of a persuasive essay. This involves reviewing the relevant mixed methods context to illustrate the problem clearly, and then stating a clear objective or purpose for the paper. Most such papers will address about three to five points. These should be written in the order laid out in the beginning, and use illustrative and persuasive examples. At the bottom of the hourglass, authors briefly summarize the key points or implications, honestly discuss limitations, and suggest broadly future implications or applications. Structurally, the introduction-persuasive argumentation-discussion typically has a 1:3-5:1 proportion in terms of word count, so a 6,000-word manuscript should have roughly a 1,000:4,000:1,000 words breakdown, though the range will be 1,000:3,000-5,000:1,000. An abstract of 120 words will roughly parallel these word proportions, 20:80:20. (p. 205)

In contrast, "original mixed methods articles are characterized by the collection and analysis 
of both qualitative and quantitative data. Authors should integrate the findings and draw inferences based on the qualitative, quantitative and mixed methods findings" (Fetters \& Freshwater, 2015, p. 205). Given these directions, the JMMR editors, currently, Professors Michael D. Fetters (Editor) and José F. Molina-Azorin (Co-Editor), provide a clear demarcation between empirical research articles and non-empirical research articles.

\subsection{Collaboration in Research/Scholarship}

Collaboration in research/scholarship occurs when two or more researchers/authors "work together on a project and contribute resources and effort, both intellectual and physical" (Subramanyam, 1983, p. 34). More specifically, Katz and Martin (1997) defined collaboration as the "working together of researchers to achieve the common goal of producing new scientific knowledge" (p. 7). As noted by Subramanyam (1983), there are several types of collaborations in research/scholarship, including the following:

- Collaboration between organizations (e.g., universities);

- Collaboration among colleagues;

- Collaboration between an instructor and her/his student(s);

- Collaboration between an advisor/supervisor and her/his doctoral student;

- Collaboration between mentor and mentee(s);

- Collaboration between researcher and consultant;

- Collaboration between consultant (e.g., program evaluation) and client; and

- International collaboration.

Further, collaboration can take many forms that range from providing general ideas, opinion, advice, or criticism (i.e., theoretical collaboration; Heffner, 1981) to participating actively through many, most, or all phases of the research project (i.e., technical collaboration; Heffner, 1981). However, for collaborators to justify having their names on a published work, they must have engaged in technical collaboration. This point is made clear by the authors of the American Psychological Association (APA) Publication Manual:

Authorship is reserved for persons who make a substantial contribution to and who accept responsibility for a published work ... Individuals should only take authorship credit for work they have actually performed or to which they have substantially contributed (APA Ethics Code Standard 8.12a, Publication Credit). Authorship encompasses, therefore, not only those who do the actual writing but also those who have made substantial scientific contributions to a study. Substantial professional contributions may include formulating the problem or hypothesis, structuring the experimental design, organizing and conducting the statistical analysis, interpreting the results, or writing a major portion of the paper. Those who so contribute are listed in the byline. Lesser contributions, which do not constitute authorship, may be acknowledged in a note (see section 2.03). These contributions may include such supportive functions as designing or 
building the apparatus, suggesting or advising about the statistical analysis, collecting or entering the data, modifying or structuring a computer program, and recruiting participants or obtaining animals. Conducting routine observations or diagnoses for use in studies does not constitute authorship. Combinations of these (and other) tasks, however, may justify authorship. (APA, 2010, p. 18)

\subsubsection{Measuring Collaboration}

A common way of measuring collaborative research patterns is via an index called the degree of collaboration. According to Subramanyam (1983), the degree of collaboration can be calculated via the following formula:

$$
\mathrm{CC}=\mathrm{NM} /(\mathrm{NM}+\mathrm{NS})
$$

Where, CC represents the degree of collaboration, NM represents the number of multiple authored papers, and NS represents the number of single-authored papers. In other words, the degree of collaboration is the ratio of the number of multi-authored journal articles to the total number of journal articles (i.e., \# of single-authored articles + \# of multiple-authored articles) (Subramanyam, 1983).

\subsection{Mixed Methods Bibliometric Study}

The present study of collaboration patterns as a function of article genre among mixed methods researchers involved the conduct of what Onwuegbuzie et al. (in press) conceptualized as a Mixed Methods Bibliometric Study. These authors posited that in mixed methods bibliometric studies, qualitative data are mixed or combined with bibliometric quantitative data for the purpose of helping researchers both to identify the patterns of publications within a given field, discipline, or body of knowledge (i.e., Quantitative phase[s]) and to understand how to these patterns have emerged (i.e., Qualitative phase[s]) in an attempt to ascertain the degree of development of various fields/disciplines/knowledge areas. Accordingly, mixed methods bibliometric studies help researchers better "to evaluate the processes of production, communication, and use of scientific information" (Vimala \& Dominic, 2013, p. 44). Thus, we deemed it appropriate to conduct a mixed methods bibliometric study to address our research questions.

\subsection{Philosophical Framework}

The research philosophical stance for our study was a recently conceptualized stance by Onwuegbuzie and Frels (2013) that they called a critical dialectical pluralistic stance. Researchers who adopt a critical dialectical pluralistic stance are concerned with social injustices that occur at Bronfenbrenner's (1979) four major levels of environment that impact a person, namely:

- The microsystem (Level 1): the immediate environment with which the person closely interacts (e.g., home, recreation center, religious institution);

- $\quad$ The mesosystem (Level 2): the other systems in which the person spends time, such as learning institution or place of work; 
- The exosystem (Level 3): the systems by which the person might be influenced but of which he/she is not directly a member, such as the relationships among teachers/instructors, the institutional administrators, the person's work supervisors, the person's parents, or other close family members; and

- The macrosystem (Level 4): the larger cultural world surrounding the person such as the society or community at large that includes societal belief systems, cultural norms, ideologies, policies, laws, or practices that indirectly influence the person.

Such concern leads critical dialectical pluralistic researchers to conduct what Onwuegbuzie, Collins, and Frels (2013) coined as micro-research studies (i.e., Level 1: research wherein one or more persons or groups are studied within his/her/their immediate environment[s]), meso-research studies (i.e., Level 2: research wherein one or more persons or groups are studied within other systems in which the he/she/they spends time), exo-research studies (i.e., Level 3: research wherein one or more persons or groups are studied within systems by which the he/she/they might be influenced but of which he/she/they is not directly a member), and macro-research studies (i.e., Level 4: research wherein one or more persons or groups are studied within the larger cultural world or society surrounding him/her/them). Moreover, uniquely, critical dialectical pluralistic researchers also are concerned with social injustices that might occur as a result of the power differential between the researcher(s) and participants. In addition to a goal of addressing social justice, critical dialectical pluralism involves incorporating multiple epistemological perspectives (Onwuegbuzie \& Frels, 2013). Accordingly, in the present research study, the researchers assumed a research-facilitator role that empowered some of the participants to assume the role of participant-researchers, who, in turn, served as co-researchers at every stage of the mixed methods research process.

\section{Method}

\subsection{Sampling Design and Sample}

For the quantitative research phase, a criterion sampling scheme was used, which involved the selection of the flagship journal for mixed methods researchers, namely, JMMR. For this journal, all articles published from 2007 (its year of inception) to 2015 (the latest complete year at the time that the study was conducted) were examined, with the exception of editorials (which are not refereed). For the qualitative phase, participants were selected via a purposive sampling scheme-specifically, a maximum variation sampling scheme (i.e., choosing participants to maximize the range of perspectives investigated in the research study; Onwuegbuzie \& Collins, 2007), wherein participants were selected in order to answer the qualitative research question (Teddlie \& Yu, 2007). Specifically, the participants for this study, which included two of the researchers who served as participant-researchers, were 14 mixed methods researchers ( 6 women and 8 men) from institutions representing various geographic areas in the United States. As demonstrated by Guest, Bunce, and Johnson (2006), 12 interviews are sufficient to "understand common perceptions and experiences among a group of relatively homogeneous individuals" (p. 79)—suggesting that our sample size was adequate for obtaining data saturation (Sandelowski, 2008) and theoretical saturation (Sandelowski, 2008). Two participants were classified as being complete member participants 
(Adler \& Adler, 1987) because they were both researchers and participants in this study. Overall, the mixed methods sampling design involved a concurrent design using nested samples for the quantitative and qualitative components of the study (Onwuegbuzie \& Collins, 2007) because the quantitative and qualitative data were collected concurrently (i.e., independently) and the vast majority (i.e., 80.0\%) of the participants selected for the qualitative research phase had authored/co-authored one or more articles in JMMR-the journal selected for the quantitative research phase.

\subsection{Mixed Methods Research Design}

Our mixed methods bibliometric study involved combining postpositivism (i.e., quantitative phase) and interpretive (hermeneutic) phenomenology (i.e., qualitative phase). This combination yielded what Mayoh and Onwuegbuzie $(2014,2015)$ referred to as mixed methods phenomenological research (MMPR) - specifically, a concurrent MMPR, which consisted of a dominant interpretive phenomenological phase (i.e., "seek[ing] to elucidate or make explicit our understanding of human behaviours and actions"; Allen \& Jensen, 1990, p. 244) and a less-dominant postpositivist phase (i.e., PHEN+quan).

For the quantitative phase, the researchers determined the number of authors contained in each article across all the journals. Also, we noted the genre of each article. For the qualitative phase, the researchers interviewed several leading mixed methods researchers using a semi-structured format. As recommended by Onwuegbuzie, Leech, and Collins (2008), the interviewers underwent debriefing interviews themselves in order to promote reflexivity.

\subsection{Analysis}

\subsubsection{Quantitative Analyses}

In the quantitative phase, we used both descriptive analyses and inferential analyses. Specifically, our descriptive analyses involved the use of descriptive statistics to assess both the proportion of empirical and non-empirical research articles, and the degree of collaboration, which comprised a measure of central tendency (i.e., frequency counts) and measures of distributional shape (i.e., skewness, kurtosis). Our inferential analyses involved (a) a Fisher's Exact Test to assess the relationship between the genre of articles published in a select mixed methods research journal and degree of collaboration in these articles, and (b) a nonparametric $t$ test to examine the difference between the number of authors in empirical research articles versus non-empirical research articles published in $J M M R$. Effect sizes were reported for all statistically significant findings.

\subsubsection{Qualitative Analyses}

We used constant comparison analysis (i.e., Glaser, 1965) via QDA Miner Version 4.1 (Provalis Research, 2015), which is a computer-assisted mixed methods data analysis software program that can be used to code, to annotate, to retrieve, and to analyze both images and a variety of text-based file formats. Our main objective in conducting a constant comparison analysis was to generate themes from the participants' responses (Glaser, 1965). 
Using Constas's (1992) typology, both the locus of theme and the naming of themes development was investigative, stemming from the intellectual constructions of the researchers. Also, the verification component of categorization was participative (Constas, 1992), stemming from the participant-researchers who verified each emergent theme. This verification approach was accomplished a posteriori (Constas, 1992).

\subsubsection{Mixed Analyses}

Overall, both a concurrent mixed analysis and sequential mixed analysis (Onwuegbuzie \& Combs, 2010; Onwuegbuzie \& Teddlie, 2003) were used. With respect to the concurrent mixed analysis, the analysis of the (quantitative) bibliometric data occurred independently of the analysis of the (qualitative) interview data. However, as part of the analysis of the interview data, a sequential mixed analysis ensued. Specifically, after the qualitative coding process, we transformed the qualitative themes that emerged into data that could be analyzed descriptively (i.e., quantitizing; cf. Miles \& Huberman, 1994; Onwuegbuzie \& Teddlie, 2003; Sandelowski, Voils, \& Knafl, 2009; Tashakkori \& Teddlie, 1998).

\section{Results}

\subsection{Quantitative Phase}

An analysis of the 163 articles published in JMMR from 2007 (its inception) to 2015 revealed that nearly two thirds (i.e., 63.2\%) of the articles represented empirical research. This difference between these two genres of research articles was statistically significant ( $p$ $<.0005)$. The effect size, as measured by the difference in percentages, was large at $26.4 \%$.

With regard to level of collaboration across these 9 years, the number of authors per manuscript ranged from 1 to $10(M=2.71, S D=1.68)$. Interestingly, $71.8 \%$ of the articles involved more than one author-which yielded the degree of collaboration. Further, whereas $28.2 \%$ of articles involved one author, $23.3 \%$ involved two authors, $23.3 \%$ involved three authors, $11.7 \%$ involved four authors, $7.4 \%$ involved five authors, $3.7 \%$ involved six authors, $1.2 \%$ involved seven authors, and $1.2 \%$ involved 10 authors - with the latter representing the number of authors who co-wrote the current article.

Table 1 presents the publication rate by genre for each of the 9 full years of JMMR's existence. It can be seen from this table that the proportion of empirical research articles exceeded the proportion of non-empirical research articles for 7 out of the 9 years. In 2010, there was an equal number of empirical research articles and non-empirical research articles, whereas in 2012, there was a higher proportion of non-empirical research articles (i.e., $58.3 \%)$. Overall, a statistically significantly $\left(\chi^{2}[1]=9.95, p=.002\right.$, Fisher's Exact Test $=.002$, Cramer's $V=.25$ ) higher degree of collaboration emerged for empirical research articles $(80.6 \%)$ than for non-empirical research articles (57.6\%). Moreover, empirical research articles were 1.4 times $(95 \%$ confidence interval $=1.10,1.78)$ more likely to involve multiple authors than were non-empirical research articles. 
Table 1. Publication rate by genre of article by year

\begin{tabular}{|l|l|l|}
\hline Year & Empirical Research Articles (\%) & Non-Empirical Research Articles (\%) \\
\hline 2007 & 60.0 & 40.0 \\
\hline 2008 & 73.3 & 26.7 \\
\hline 2009 & 58.8 & 41.2 \\
\hline 2010 & 50.0 & 50.0 \\
\hline 2011 & 81.3 & 18.7 \\
\hline 2012 & 41.7 & 58.3 \\
\hline 2013 & 68.4 & 31.6 \\
\hline 2014 & 69.6 & 30.4 \\
\hline 2015 & 76.5 & 23.5 \\
\hline
\end{tabular}

Onwuegbuzie and Daniel (2002) developed criteria for a standardized skewness coefficient (i.e., skewness coefficient divided by its standard error) and a standardized kurtosis coefficient (i.e., kurtosis coefficient divided by its standard error), wherein standardized skewness coefficients and/or standardized kurtosis coefficients that lie outside the \pm 3 range indicate serious departures from normality. Using these criteria, the number of authors indicated a serious departure from normality because both the standardized skewness coefficient $(1.42 / 0.19=7.47)$ — which indicated positive skew — and the standardized kurtosis coefficient $(3.16 / 0.38=8.32)$-which indicated leptokurtic distribution that was characterized by a shape that was more peaked - were far outside the range of normality. Therefore, a nonparametric inferential test-specifically, Mann-Whitney's $U$ test-was used to compare the number of authors involved in empirical research articles to those involved in non-empirical research articles for each year and across all 9 years. After applying the Bonferroni adjustment, this series of tests revealed no statistically significant difference in the number of authors between the two genres of research articles for any of the 9 individual years (see Table 2). However, a statistically significant difference emerged overall $(U=$ 2292.00, $p=.004)$, with empirical research articles $(M=2.89, S D=1.56)$ containing more authors than did non-empirical research articles $(M=2.42, S D=1.86)$. Cohen's (1988) $d$ effect size associated with this difference was 0.28 . 


\section{Macrothink}

Table 2. Mean and standard deviation of number of authors as a function of genre and year

\begin{tabular}{|l|l|l|l|l|l|}
\hline \multirow{2}{*}{ Year } & \multicolumn{2}{|l|}{ Empirical Research Articles } & \multicolumn{2}{l|}{ Non-Empirical Research Articles } & \multirow{2}{*}{ Mann-Whitey's $U^{*}$} \\
\cline { 2 - 5 } & $M$ & $S D$ & $M$ & $S D$ & \\
\hline 2007 & 3.00 & 1.66 & 2.50 & 1.87 & 20.50 \\
\hline 2008 & 2.64 & 1.03 & 1.50 & 0.58 & 7.00 \\
\hline 2009 & 3.40 & 2.63 & 1.71 & 0.76 & 18.00 \\
\hline 2010 & 3.00 & 1.85 & 2.50 & 1.41 & 27.00 \\
\hline 2011 & 3.54 & 1.81 & 2.33 & 1.16 & 11.00 \\
\hline 2012 & 2.40 & 1.27 & 2.71 & 2.05 & 69.50 \\
\hline 2013 & 2.92 & 1.26 & 3.17 & 3.55 & 29.50 \\
\hline 2014 & 2.63 & 1.36 & 1.86 & 1.46 & 35.00 \\
\hline 2015 & 2.62 & 1.12 & 3.25 & 2.22 & 22.00 \\
\hline Total & 2.89 & 1.56 & 2.42 & 1.86 & $2292.00^{*}$ \\
\hline
\end{tabular}

Note. * None of the Mann-Whitney $U$ statistics were statistically significant at the Bonferroni-adjusted level of .005 (i.e., .05/10 comparisons). However, across all 10 years (see "Total" row), the Mann-Whitney $U$ statistic was statistically significant, $p=.004$.

\subsection{Qualitative Phase}

To investigate the link between collaboration and article genre, a subset of eight mixed methods researchers' transcripts of the 14 available transcripts were examined because they each substantively mentioned research genres. As noted previously, a constant comparison analysis (Glaser, 1965) was used to identify significant themes and ideas inherent in the eight transcripts (Ryan \& Bernard, 2000). Initially, descriptive labels (i.e., codes) were identified and categorized, thereby establishing themes intrinsic to the data (Straus \& Corbin, 1998). This process allowed for the identification of 16 separate codes composing four themes (i.e., mental perception, mixed methods research, publication and research aids, and independent/group work), detailed in Table 3. Each of these themes is discussed in the following sections. 


\section{Macrothink}

Table 3. Themes and codes identified using constant comparative analysis

\begin{tabular}{|c|c|}
\hline Themes & Codes \\
\hline \multirow{5}{*}{ Mental Perception } & Difficulty \\
\hline & Perceived Strengths \\
\hline & Perceived Weaknesses \\
\hline & Lack of Confidence \\
\hline & Need for Answers \\
\hline \multirow[t]{4}{*}{ Publication and Research Aids } & Mentorship \\
\hline & Helpful Articles \\
\hline & Skill Specialization \\
\hline & Pressures to Publish \\
\hline \multirow[t]{3}{*}{ Mixed Methods Research } & Time Needed \\
\hline & Process and Procedures \\
\hline & Level of Work \\
\hline \multirow[t]{4}{*}{ Independent/Group Work } & Independent Research - Experience \\
\hline & Independent Research - Preferences \\
\hline & Group Research - Experiences \\
\hline & Group Research - Preferences \\
\hline
\end{tabular}

\subsubsection{Mental Perception}

Findings from the mental perception theme revealed that one half of the participants expressed thoughts and made statements regarding mental perception. These four participants (Drs. Robin, Alfred, Gunn, and Victoria - these names and all others are pseudonyms) all indicated that they identified empirical research, specifically in the form of statistics or quantitative research, as their personal strength. (In contrast, none of the participants claimed qualitative research methodology as one of their personal strengths.) Of these four participants, two of them, Dr. Victoria and Dr. Alfred, discussed their beliefs in greater detail than did the others.

Dr. Victoria went so far as to say "I'm more confident with empirical research, because it's rather about finding a good design, I guess, or creating a good design. And like I said, it can be messy also. And confidence can be hard solo," thereby indicating the importance of collaboration in research. Dr. Victoria expounded on this when she stated that "some of the mixed methods design models ... are a little over my head" (perceived weakness) and she did not "have the confidence to put myself out there as a methodologist" (lack of confidence).

Despite Dr. Alfred being told that he "probably [has] more of a quantitative learning 
compared to a lot of my colleagues," he was very quick to emphasize the difficulty inherent in both empirical and mixed methods research in that

Sometimes people will work on concurrent designs where they're doing their qualitative and quantitative phases all at once. But as you can imagine, they're not going to sleep a lot unless they have a relatively easy access to data and things run in a straightforward manner. I find that in most of the empirical side of the world, research doesn't really work that way. It's complicated.

However, despite this difficulty, Dr. Alfred articulated his need for answers concerning research, as evidenced by his statement concerning his participation in this research:

I'm kind of curious as to the results of your work because at some point you'll be looking at how many mixed methods pieces are in fact sole authored that are out there. Empirically speaking, I'm curious about that because my expectation is that if you're really looking at data-driven articles that's probably a minority.

Intriguingly, Dr. Alfred's anecdotal belief that collaboration would be more likely to occur in empirical-based studies corroborated the findings of the bibliometric analysis. Interestingly, Dr. Alfred further revealed that he suspected that "I'm probably not so very different from my colleagues in the sense that I don't have too many single-authored pieces in the mixed methods world."

\subsubsection{Mixed Methods Research}

Although only three of the eight participants explicitly discussed mixed methods research in regards to both collaboration and genre, they all emphasized the importance of collaboration within mixed methods research, regardless of genre. Dr. Alfred and Dr. Hopkins both emphasized that, within mixed methods research, empirical articles are easier for individuals working alone. Dr. Hopkins explained his claim in that empirical articles "are easier to manage because they have natural parts. You have an intro[duction], lit[erature] review, methods, results, discussion ... you do this, [then] you do that." Although Dr. Alfred agreed with Dr. Hopkins's belief that empirical research is easier in the mixed methods research arena, he cautioned that "If you're doing empirical mixed methods research, be very careful of your time. If you can imagine ... If you're going to do a sequential study or multiphase study where you're going qual, quant, qual, quant, whatever."

Dr. Hopkins explained the difficulties inherent in collaborating when conducting methodological research by stating that,

When it comes to methodological, [it's] very different because it's somebody's idea and most of the time, somebody has to start it off. You can't just say you have this idea, you have that idea. Somebody has to take the lead and start it off. Now, there might be situations where there are parts. You can say okay, can you write about X? Can you write about Y? But, in general, someone has to map it out and that's why the distribution of labor in methodological or conceptual articles is usually less equitable than in studies.

Based on this statement, along with the other comments regarding the time needed for and the 
in-depth processes and procedures inherent in mixed methods research, especially when dealing with methodological research, Dr. Gunn's comment, "I think it's really difficult to find that skillset to conduct a mixed method study within a single person," is understandable.

\subsubsection{Publication and Research Aids}

This theme comprised the following four subthemes: (a) skill specialization, (b) mentorship, (c) useful articles, and (d) pressures to publish. Specifically, four of the eight participants made comments associated with this theme. However, their comments alluded to important issues concerning collaboration in regards to article genre.

Dr. Gunn referenced the difficulty in developing all of the necessary skills for mixed methods research. Dr. Alfred concurred and argued for the common occurrence of skill specialization as

... it's really unusual for a person to have top-of-the-line skill sets in all those disparate areas just between one pair of ears. You usually need a group of people with different skills and abilities that you can pull together so that you can rely on each other to work on what they're good at.

Although these two statements reference the breadth and depth needed regarding skills within mixed methods research, one can use context clues to identify the importance of collaboration within mixed methods research.

Given the importance of developing skills, both Dr. Gunn and Dr. Folgers mentioned mentorship as being an important factor within the research and publication arenas. Dr. Gunn advocated that less experienced researchers "find someone who's a little bit more senior" and "has been through it" as "there's quite a bit of wisdom to share." Dr. Folgers offered advice via the role of an experienced researcher, arguing that helping inexperienced researchers helps the entire mixed methods research process and, in turn, helps them learn about it by working on the literature review, researching articles, and "for empirical articles, doing some of the data analysis." By acting as a mentor, Dr. Gunn contended that experienced researchers have "an opportunity to learn through it too and make the most of it."

Beyond mentorship, two of the participants argued for the identification of and use of helpful articles. Dr. Hopkins argued that researchers should find exemplars that match the genre of the article that one is writing. Whereas Dr. Hopkins advocated helpful articles to match whatever genre is being written, Dr. Alfred argued the importance of background research when "doing mixed methods pieces where they are thought pieces [i.e., conceptual or methodological]." Dr. Alfred even went so far as to argue that the preeminent mixed methods researchers in the field "have a number of single-authored pieces, but they're not necessarily empirical in orientation," thereby implying that collaboration is more common in empirical research than in non-empirical research.

Because Dr. Alfred was a very vocal participant, he also expounded on the implications of collaboration in regards to genre and academic promotions (i.e., publish or perish). Specifically, he stated that, 
If it turns out that I'm right that a lot of the empirical mixed methods articles that are out there in fact co-authored pieces that's actually something that I think an assistant professor would want to bring to a tenure committee. And say, "Look you hired me to be a mixed methods person. Everybody else is working in teams, so don't count it against me if I am doing this." Because that's kind of a subject-specific issue.

Dr. Alfred alluded to the educational and professional significance of the study as it might impact the careers of academics regarding promotion and publication practices, especially with regard to article genre and collaboration.

\subsubsection{Independent/Group Work}

The fourth and most expansive theme was that of independent/group work, in which six of the eight participants contributed. This theme, composed of four subthemes, related the participants' views and experiences concerning collaboration. Only two participants mentioned a preference for independent work, Dr. Folger and Dr. Hopkins, with the former preferring independent work in all situations whereas the latter only preferred independent work in specific situations.

Two participants in particular, Dr. Folger and Dr. Hopkins, offered elaboration as to why they preferred to work alone. Dr. Folger, the only participant who preferred independent research, stated,

I tend to be very much of a lone ranger in my own work. I don't seek out collaborators that often because I have my own way of thinking about things. I disagree with a lot of other people. For me, it's usually easier to work on my own.

More specifically, in reference to group research and methodological writing, Dr. Folger claimed, "co-authorship has often been more trouble than it's been worth." However, with regard to empirical research, Dr. Folger argued, "there's a much bigger advantage to collaborating."

Similar to Dr. Folger, Dr. Hopkins preferred to work alone when dealing with methodological or conceptual articles as "a couple of those articles ... were controversial" and he did not want others to get "flak" for his ideas. He reasoned that "if someone was going to be mad, I wanted them to be mad at me because I was ... basically criticizing those who criticize mixed $\operatorname{method}[\mathrm{s}]$ without providing any evidence." Despite Dr. Hopkins's willingness to fall on the proverbial sword for his work, he was very quick to emphasize that he would "much rather work in teams." In essence, the only reason that Dr. Hopkins preferred to work alone, in contrast to Dr. Folger's "lone ranger" mentality, was to spare others from potential fallout related to controversial topics.

Several of the participants discussed their personal experiences regarding their work. Dr. Baker, despite preferences for methodological and conceptual research, articulated that he worked in many groups and that these groups "did empirical research but we almost always did research together." Interestingly, the only independent empirical study that Dr. Baker recalled conducting was for his dissertation. Similarly, Dr. Trump, a researcher with years of 
experience, reported only conducting independent mixed methods research twice and that the greatest challenge was "bringing in not just the empirical mixed methods, but the theoretical part of mixed methods." Dr. Trump further discussed the necessity of sole-authored articles for tenure and declared that "the majority of my publications are focused on theoretical or methodological papers" for this very reason.

Dr. Gunn favored independent work in context with empirical research studies because it tended to be a somewhat more straightforward; however,

when working on a conceptual piece, something that's methodological ... for me, working with others is extremely beneficial in terms how to organize it, ... copyediting issues, ... looking at the general flow of ideas and ..., working that out together and seeing what there were actually building something that's coherent or not um, is a, it's really useful for me to do it with others as opposed to independently.

During one of his collaborations, Dr. Gunn had "a paper that was clearly more empirical and it went well," but the fellow collaborator raised the following question, "do we really have a methodological contribution here too?" Dr. Gunn admitted that he

wouldn't have really seen that on my own. I would have been on to the next thing, you know through that conversation we did, and that led to another paper. That's been a benefit of working with others and a reason I would prefer to do that again.

Dr. Trump corroborated this sentiment when she stated that she enjoyed working in a group because the additional researchers brought "different methodological abilities" and "different theoretical perspectives" to the process. Moreover, Dr. Trump, along with Dr. Hopkins, Dr. Victoria, and Dr. Robin, advocated for group work based on their own enjoyment of the process - as Dr. Trump put it, "it's just fun” to work in a group.

\section{Discussion}

This investigation was unique in at least three ways. First, the present work appears to represent the first in which the degree of collaboration rates has been compared as a function of article genre. Second, this study is one of the first to mix a qualitative research approach with bibliometric techniques, yielding what Onwuegbuzie et al. (in press) call a mixed methods bibliometric study. Third, because $J M M R$ is a multidisciplinary journal and the participants selected for the qualitative phase represented various disciplines (e.g., education, psychology, health), both phases of this mixed methods bibliometric study were multidisciplinary in nature.

\subsection{Validating/Legitimating the Findings}

We used the meta-framework of Benge, Onwuegbuzie, and Robbins (2012) to assess threats to legitimation pertaining to the quantitative findings, qualitative findings, and mixed methods research findings. This meta-framework incorporates frameworks that have been conceptualized to assess threats to the internal validity and external validity of the findings pertaining to the quantitative component (e.g., Campbell, 1957; Onwuegbuzie, 2003), threats to the internal credibility and external credibility of the results relating to the qualitative 
component (e.g., Maxwell, 1992; Onwuegbuzie \& Leech, 2007), and threats to the legitimation of the findings stemming from the mixed methods component (Onwuegbuzie \& Johnson, 2006).

\subsection{Validity of Findings from Quantitative Phase}

With respect to the internal validity of the quantitative findings, our overall sample size of 163 articles indicates that we had more than sufficient statistical power to conduct our inferential analyses (i.e., Fisher's Exact Test, Mann-Whitney $U$ tests). Thus, our overall sample size did not pose a serious threat to the internal validity of the findings. In addition, our high inter-rater reliability (i.e., inter-coder agreement) of 100\% helped to eliminate instrumentation as a threat to internal validity.

With regard to external validity, the fact that $J M M R$ currently represents the only journal devoted exclusively to mixed methods research articles and that every peer-reviewed article was examined that had been published in JMMR at the time of the study suggests that our quantitative (i.e., bibliometric) findings might be generalizable (i.e., have adequate external validity). However, replications of this study are needed examining mixed methods research articles published in other journals. In particular, we recommend that these future studies involve the use of mixed methods research approaches.

\subsection{Legitimation of Findings from Qualitative Phase}

With respect to internal credibility, the biggest threats to the findings were descriptive validity (i.e., the factual accuracy of the account; Maxwell, 1992) and interpretive validity (i.e., the extent to which our interpretations of these accounts provide an understanding of the mixed methods researchers' collaboration experiences and the meanings that they attach to their words and experiences; Maxwell, 1992). Descriptive validity was enhanced by the fact that all participants member-checked the transcripts for accuracy, adequacy, and authenticity (Lincoln \& Guba, 1985; Manning, 1997). Interpretive validity was enhanced by the participant-researchers reading the interpretations and verifying the emergent themes, as well as via the debriefing interviews that were conducted on those who interviewed the research participants (Onwuegbuzie et al., 2008).

With respect to external credibility, the sample size of 14 used in the qualitative phase far exceeded Guest et al.'s (2006) sample recommendation for achieving data saturation utilizing a relatively homogeneous sample (i.e., mixed methods researchers). This sample size, coupled with the fact that little additional information was provided by the participants at the member-checking phase, suggest that data saturation very likely took place. Interestingly, data saturation was confirmed by the two participant-researchers regarding their own interviews.

\subsection{Legitimation of Findings from the Mixed Methods Research Phase}

Onwuegbuzie and Johnson (2006) identified nine legitimation types that are relevant to mixed methods research. Each of these legitimation types is defined in Table 4, together with an explanation of how they were addressed in our investigation. This table indicates that all 
nine threats were addressed to some degree. Notwithstanding, despite the extremely rigorous nature of the mixed methods research design, replications of this mixed methods bibliometric study are needed to assess the reliability and transferability of these findings.

Table 4. Typology of mixed methods legitimation types

\begin{tabular}{|c|c|c|}
\hline Legitimation Type & Description & How Legitimation Type was Enhanced \\
\hline Sample Integration & $\begin{array}{l}\text { The extent to which the relationship } \\
\text { between the quantitative and } \\
\text { qualitative sampling designs yields } \\
\text { quality meta-inferences. }\end{array}$ & $\begin{array}{l}\text { Using a nested sampling design in which the } \\
\text { vast majority (i.e., } 80.0 \% \text { ) of the participants } \\
\text { selected for the qualitative research phase } \\
\text { had authored/co-authored one or more } \\
\text { articles that were published in } J M M R\end{array}$ \\
\hline Inside-Outside & $\begin{array}{l}\text { The extent to which the researcher } \\
\text { accurately presents and appropriately } \\
\text { utilizes the insider's view and the } \\
\text { observer's views for purposes such as } \\
\text { description and explanation. }\end{array}$ & $\begin{array}{l}\text { Capturing the participants' quantitative and } \\
\text { qualitative data (i.e., emic [i.e., insider's] } \\
\text { perspective) and including two participants } \\
\text { on the research team (i.e., emtic [i.e., } \\
\text { insider's and outsider's] perspective; } \\
\text { Onwuegbuzie, 2012) }\end{array}$ \\
\hline $\begin{array}{l}\text { Weakness } \\
\text { Minimization }\end{array}$ & $\begin{array}{l}\text { The extent to which the weakness from } \\
\text { one approach is compensated by the } \\
\text { strengths from the other approach. }\end{array}$ & $\begin{array}{l}\text { Combining empirical precision (i.e., } \\
\text { obtained from quantitative analyses) with } \\
\text { descriptive precision (i.e., obtained from } \\
\text { qualitative analyses) }\end{array}$ \\
\hline Sequential & $\begin{array}{l}\text { The extent to which one has minimized } \\
\text { the potential problem wherein the } \\
\text { meta-inferences could be affected by } \\
\text { reversing the sequence of the } \\
\text { quantitative and qualitative phases. }\end{array}$ & $\begin{array}{l}\text { Collecting quantitative and qualitative data } \\
\text { simultaneously (i.e., concurrently) }\end{array}$ \\
\hline Conversion & $\begin{array}{l}\text { The extent to which the quantitizing or } \\
\text { qualitizing yields quality } \\
\text { meta-inferences. }\end{array}$ & $\begin{array}{l}\text { Obtaining verification of quantitative } \\
\text { analyses of themes via member checking } \\
\text { and debriefing }\end{array}$ \\
\hline $\begin{array}{l}\text { Paradigmatic } \\
\text { Mixing }\end{array}$ & $\begin{array}{l}\text { The extent to which the researcher's } \\
\text { epistemological, ontological, } \\
\text { axiological, methodological, and } \\
\text { rhetorical beliefs that underlie the } \\
\text { quantitative and qualitative approaches } \\
\text { are successfully (a) combined or (b) } \\
\text { blended into a usable package. }\end{array}$ & $\begin{array}{l}\text { Adopting a critical dialectical stance } \\
\text { (Onwuegbuzie \& Frels, 2013) that represents } \\
\text { a meta-paradigm wherein multiple } \\
\text { epistemological perspectives are } \\
\text { incorporated within the same inquiry } \\
\text { (Johnson, 2011, 2012) }\end{array}$ \\
\hline Commensurability & $\begin{array}{l}\text { The extent to which the } \\
\text { meta-inferences made reflect a mixed } \\
\text { worldview based on the cognitive } \\
\text { process of Gestalt switching and } \\
\text { integration. }\end{array}$ & $\begin{array}{l}\text { By using a team of researchers that was } \\
\text { diverse with respect to research training, } \\
\text { research experience, and discipline (e.g., } \\
\text { higher education, literacy, library science, } \\
\text { research methodologist) }\end{array}$ \\
\hline
\end{tabular}




\begin{tabular}{|l|l|l|}
\hline Multiple Validities & $\begin{array}{l}\text { The extent to which addressing } \\
\text { legitimation of the quantitative and } \\
\text { qualitative components of the study } \\
\text { result from the use of quantitative, } \\
\text { qualitative, and mixed validity types, } \\
\text { yielding high quality meta-inferences. }\end{array}$ & $\begin{array}{l}\text { Using techniques (e.g., inter-coder } \\
\text { agreement, member checking, debriefing) } \\
\text { that addressed as many threats to the } \\
\text { legitimation of both the qualitative and } \\
\text { quantitative findings as possible }\end{array}$ \\
\hline Political & $\begin{array}{l}\text { The extent to which the consumers of } \\
\text { mixed methods research value the } \\
\text { meta-inferences stemming from both } \\
\text { the quantitative and qualitative } \\
\text { components of a study. }\end{array}$ & $\begin{array}{l}\text { Using rigorous qualitative and quantitative } \\
\text { research techniques }\end{array}$ \\
\hline
\end{tabular}

Note. This table was adapted from Onwuegbuzie and Johnson (2006). Reprinted with kind permission of the Mid-South Educational Research Association and the Editors of Research in the Schools.

\subsection{Interpretation of the Findings}

Several findings emerged from the quantitative research phase of our mixed methods bibliometric study. First and foremost, approximately two thirds (i.e., 63.2\%) of the articles represented empirical research articles. This finding suggests one or more of the following possibilities: (a) mixed methods researchers are producing almost twice as many empirical research articles as they produce non-empirical research articles; (b) mixed methods researchers are more likely to submit their non-empirical research manuscripts to other journals than they are to submit their empirical research articles; and/or (c) non-empirical research articles are being rejected by the seven $J M M R$ editors since the journal's inception at a higher rate than are empirical research articles. Unfortunately, it is beyond the scope of the present investigation to assess the likelihood of the latter possibility. However, we do intend to conduct a follow-up study wherein we interview one or more past or present JMMR editors to determine the manuscript rejection trends. Notwithstanding, the first two possibilities can be assessed, in part, by referring to the seminal work by Ivankova and Kawamura (2010). These authors, who examined five major databases (i.e., PubMed, ERIC, PsychInfo, Academic One File, and Academic Search Premier) that represented 10 subject areas (i.e., business, communication studies, education, health and medicine, library studies, political studies, psychology, social work, sociology, women's studies) and two mixed methods research journals (i.e., International Journal of Multiple Research Approaches and Journal of Mixed Methods Research), from January 2000 to April 2009, identified 802 mixed methods research articles, of which 689 represented empirical research articles and 113 represented methodological research articles. This finding indicates that the non-empirical research articles represented $14.1 \%$ of the total research articles extracted by Ivankova and Kawamura (2010) — which is less than the $36.8 \%$ of non-empirical research articles published in JMMR. More specifically, for 2008, the last complete year examined by these researchers, they identified 243 empirical research articles and 22 methodological research articles, indicating 
that the non-empirical research articles represented $8.3 \%$ of the total research articles-compared to the $26.7 \%$ of non-empirical research articles published in JMMR during the same year. Thus, in reference to the first two possibilities stated earlier, our comparisons made to Ivankova and Kawamura's (2010) findings suggest that mixed methods researchers are more likely to submit their non-empirical research manuscripts to JMMR than to other journals, which further indicates that our finding that mixed methods researchers are producing almost twice as many empirical research articles as they produce non-empirical research articles likely represents an underestimate. And for a field that is still advancing, this conclusion suggests that more non-empirical mixed methods research articles perhaps should be encouraged by the $J M M R$ editors and editors of other journals who publish mixed methods research articles. Interestingly, when we conducted a citation analysis using Harzing's (2009) Publish or Perish software, we discovered that nine of the 10 most cited refereed articles (i.e., not including editorials) published in $J M M R$ represent non-empirical research articles. And, at the time of writing, these nine non-empirical research articles have attained 11,543 citations out of the total 21,125 citation received by all JMMR articles, representing $54.6 \%$ of the total number of citations. Indeed, the top three most cited articles - namely, Johnson, Onwuegbuzie, and Turner (2007), Morgan (2007), and Teddlie and Yu (2007), respectively - which are all non-empirical research articles, have received $33.7 \%$ of the total number of citations! Thus, it can be argued that non-empirical research articles are influencing the field of mixed methods research to a significantly greater degree than are empirical research articles - supporting our recommendation that a higher rate of submission of non-empirical research articles be encouraged by editors of $J M M R$ and beyond. One way of accomplishing more non-empirical research articles is for the JMMR editors to publish a special issue on a methodological topic. Indeed, such a special issue explains why 2012 yielded more non-empirical research articles (58.3\%) published than empirical research articles $(41.7 \%)$ - the only year where this occurred - when a special issue on triangulation was published. Interestingly, at the time of writing, the non-empirical research articles in this special issue already have garnered 1,175 citations (5.6\% of the total JMMR citations). The qualitative findings also appear to support our recommendation for more non-empirical research articles in general and methodological articles in particular. Indeed, some of these participants highlighted the importance of exemplar articles that would be helpful not only to mixed methods researchers as they write their articles but also during the mentoring process.

Another interesting quantitative research finding was the statistically significantly higher degree of collaboration for empirical research articles $(80.6 \%)$ than for non-empirical research articles $(57.6 \%)$, with empirical research articles, on average, being nearly 1.40 times more likely to involve multiple authors than were non-empirical research articles. Further, empirical research articles contained statistically significantly more authors than did non-empirical research articles. A related finding was that whereas only $19.4 \%$ of empirical research articles involved only one author, $42.4 \%$ of non-empirical research articles involved single authorship. Interestingly, the years 2012, 2013, and 2015 witnessed a higher number of authors for non-empirical research articles than for empirical research articles. These years suggest that the number of authors involved in non-empirical research articles might be increasing in recent years. To the extent that this trend continues, future researchers should 
explore reasons for this new phenomenon.

This finding regarding the greater propensity for non-empirical research articles to involve single authorship is consistent with the qualitative findings. Indeed, this result has intuitive appeal because, as noted by one of the participants, the division of labor is easier to organize for empirical research articles because they are more formulaic - that is, they almost always contain introduction/literature review, method, result, and discussion sections. And different authors can be assigned to the different sections in these articles. On the other hand, non-empirical research articles usually arise from the conceptualization of the lead author, and, unless the article has distinct components, it likely would be more challenging to assign roles - especially in an equitable manner. Also, the qualitative findings regarding the theme of mental perception suggest that another reason why empirical research involves the use of more authors is because many, if not most, mixed methods researchers tend to be stronger in either quantitative research methodology or qualitative research methodology. As such, they enlist the help of co-authors to help fill any actual or perceived deficits that they have in their weaker methodology.

Analysis of the qualitative data stemming from the eight participants who provided substantive discussion related to the topic of genre of mixed methods research articles revealed four themes and several subthemes, which indicates that the issue of genre represents a multi-dimensional construct. Future qualitative investigations should explore further this multidimensionality, as well as the group dynamics involved in both these genres of mixed methods research articles. Information gleaned from such investigations likely will help mixed methods researchers make optimal decisions about collaboration in their works.

\section{References}

Adler, P. A., \& Adler, P. (1987). Membership roles in field research. Beverly Hills, CA: Sage. https://doi.org/10.4135/9781412984973

Allen, M. N., \& Jensen, L. (1990). Hermeneutical inquiry: Meaning and scope. Western Journal of Nursing Research, 12, 241-253. https://doi.org/10.1177/019394599001200209

American Psychological Association. (2010). Publication manual of the American Psychological Association (6th ed.). Washington, D.C.: Author.

Benge, C. L., Onwuegbuzie, A. J., \& Robbins, M. E. (2012). A model for presenting threats to legitimation at the planning and interpretation phases in the quantitative, qualitative, and mixed research components of a dissertation. International Journal of Education, 4, 65-124. https://doi.org/10.5296/ije.v4i4.2360

Bronfenbrenner, U. (1979). The ecology of human development: Experiments by nature and design. Cambridge, MA: Harvard University Press.

Campbell, D. T. (1957). Factors relevant to the validity of experiments in social settings. Psychological Bulletin, 54, 297-312. https://doi.org/10.1037/h0040950

Cohen, J. (1988). Statistical power analysis for the behavioral sciences (2nd ed.). Hillsdale, 
NJ: Lawrence Erlbaum.

Constas, M. A. (1992). Qualitative data analysis as a public event: The documentation of category development procedures. American Educational Research Journal, 29, 253-266. https://doi.org/10.3102/00028312029002253

Fetters, M. D., \& Freshwater, D. (2015). Publishing a methodological mixed methods research article. Journal of Mixed Methods Research, 9, 203-213. https://doi.org/10.1177/155 8689815594687

Fisher, B. S., Cobane, C. T., Ven, T. M. V., \& Cullen, F. T. (1998). How many authors does it take to publish an article? Trends and patterns in political science. PS: Political Science and Politics, 31, 847-856. https://doi.org/10.2307/420730

Glaser, B. G. (1965). The constant comparative method of qualitative analysis. Social Problems, 12, 436-445. https://doi.org/10.1525/sp.1965.12.4.03a00070

Guest, G., Bunce, A., \& Johnson, L. (2006). How many interviews are enough? An experiment with data saturation and variability, Field Methods, 18, 59-82. https://doi.org/ $10.1177 / 1525822$ X05279903

Harzing, A. W. K. (January, 2009). Publish or perish. Retrieved from http://www.harzing. com/pop.htm

Heffner, A. G. (1981). Funded research, multiple authorship, and subauthorship collaboration in four disciplines. Scientometrics, 3, 5-12. https://doi.org/10.1007/BF02021860

Ivankova, N. V., \& Kawamura, Y. (2010). Emerging trends in the utilization of integrated designs in the social, behavioral, and health sciences. In A. Tashakkori \& C. Teddlie (Eds.), Sage handbook of mixed methods in social and behavioral research (2nd ed., pp. 581-611). Thousand Oaks, CA: Sage. https://doi.org/10.4135/9781506335193.n23

Johnson, R. B. (2011). Dialectical pluralism: A metaparadigm to help us hear and "combine" our valued differences. In S. J. Hesse-Biber (Chair), Addressing the Credibility of Evidence in Mixed Methods Research: Questions, Issues and Research Strategies. Plenary conducted at the meeting of Seventh International Congress of Qualitative Inquiry, University of Illinois at Urbana-Champaign.

Johnson, R. B. (2012). Dialectical pluralism and mixed research. American Behavioral Scientist, 56, 751-754. https://doi.org/10.1177/0002764212442494

Johnson, R. B., \& Onwuegbuzie, A. J. (2004). Mixed methods research: A research paradigm whose time has come. Educational Researcher, 33(7), 14-26. https://doi.org/10.1177/1558689 806298224

Johnson, R. B., Onwuegbuzie, A. J., \& Turner, L. A. (2007). Toward a definition of mixed methods research. Journal of Mixed Methods Research, 1, 112-133. https://doi.org/10.1525/ sp.1960.8.2.03a00030

Katz, J. S., \& Martin, B. R. (1997). What is research collaboration? Research Policy, 26(1), 
1-19. https://doi.org/10.1016/S0048-7333(96)00917-1

Lincoln, Y. S., \& Guba, E. G. (1985). Naturalistic inquiry. Beverly Hills, CA: Sage.

Manning, K. (1997). Authenticity in constructivist inquiry: Methodological considerations without prescription. Qualitative Inquiry, 3, 93-115. https://doi.org/10.1177/1077800497003 00105

Maxwell, J. A. (1992). Understanding and validity in qualitative research. Harvard Educational Review, 62, 279-299. https://doi.org/10.17763/haer.62.3.8323320856251826

Mayoh, J., \& Onwuegbuzie, A. J. (2014). Surveying the landscape of mixed methods phenomenological research. International Journal of Multiple Research Approaches, 8, 2-14. https://doi.org/10.5172/mra.2014.8.1.2

Mayoh, J., \& Onwuegbuzie, A. J. (2015). Towards a conceptualization of mixed methods phenomenological research. Journal of Mixed Methods Research, 9, 91-107. https://doi.org/ $10.1177 / 1558689813505358$

Miles, M., \& Huberman, A. M. (1994). Qualitative data analysis: An expanded sourcebook (2nd ed.). Thousand Oaks, CA: Sage.

Morgan, D. L. (2007). Paradigms lost and pragmatism regained: Methodological implications of combining qualitative and quantitative methods. Journal of Mixed Methods Research, 1, 48-76. https://doi.org/10.1177/2345678906292462

Onwuegbuzie, A. J. (2003). Expanding the framework of internal and external validity in quantitative research. Research in the Schools, 10(1), 71-90.

Onwuegbuzie, A. J. (2012). Introduction: Putting the mixed back into quantitative and qualitative research in educational research and beyond: Moving towards the radical middle. International Journal of Multiple Research Approaches, 6, 192-219. https://doi.org/10.5172/ mra.2012.6.3.192

Onwuegbuzie, A. J., \& Collins, K. M. T. (2007). A typology of mixed methods sampling designs in social science research. The Qualitative Report, 12, 281-316. Retrieved from http://www.nova.edu/ssss/QR/QR12-2/Onwuegbuzie2.pdf

Onwuegbuzie, A. J., Collins, K. M. T., \& Frels, R. K. (2013). Foreword: Using Bronfenbrenner's ecological systems theory to frame quantitative, qualitative, and mixed research. International Journal of Multiple Research Approaches, 7, 2-8. https://doi.org/ 10.5172/mra.2013.7.1.2

Onwuegbuzie, A. J., \& Combs, J. P. (2010). Emergent data analysis techniques in mixed method research: A synthesis. In A. Tashakkori \& C. Teddlie (Eds.), Handbook of mixed methods in social and behavioral research (2nd ed., pp. 397-430). Thousand Oaks, CA: Sage. https://doi.org/10.4135/9781506335193.n17

Onwuegbuzie, A. J., \& Daniel, L. G. (2002). Uses and misuses of the correlation coefficient. Research in the Schools, 9(1), 73-90. 
Onwuegbuzie, A. J., \& Frels, R. K. (2013). Introduction: Toward a new research philosophy for addressing social justice issues: Critical dialectical pluralism 1.0. International Journal of Multiple Research Approaches, 7, 9-26. https://doi.org/10.5172/mra.2013.7.1.9

Onwuegbuzie, A. J., \& Frels, R. K. (2016). Seven steps to a comprehensive literature review: A multimodal and cultural approach. London, England: Sage.

Onwuegbuzie, A. J., \& Johnson, R. B. (2006). The validity issue in mixed research. Research in the Schools, 13(1), 48-63.

Onwuegbuzie, A. J., \& Leech, N. L. (2007). Validity and qualitative research: An oxymoron? Quality \& Quantity: International Journal of Methodology, 41, 233-249. https://doi.org/ 10.1007/s11135-006-9000-3

Onwuegbuzie, A. J., Leech, N. L., \& Collins, K. M. T. (2008). Interviewing the interpretive researcher: A method for addressing the crises of representation, legitimation, and praxis. International Journal of Qualitative Methods, 7(4), 1-17.

Onwuegbuzie, A. J., \& Teddlie, C. (2003). A framework for analyzing data in mixed methods research. In A. Tashakkori \& C. Teddlie (Eds.), Handbook of mixed methods in social and behavioral research (pp. 351-383). Thousand Oaks, CA: Sage.

Onwuegbuzie, A. J., Wilcox, R., Gonzales, V., Hoisington, S., Jordan, J., \& Valle, R. (in press). Collaboration patterns among mixed researchers: A multidisciplinary examination. International Journal of Multiple Research Approaches.

Plano Clark, V. L., \& Badiee, M. (2010). Research questions in mixed methods research. In A. Tashakkori \& C. Teddlie (Eds.), Sage handbook of mixed methods in social and behavioral research (2nd ed., pp. 275-304). Thousand Oaks, CA: Sage. https://doi.org/10.4135/9781506 335193.n12

Provalis Research. (2015). QDA Miner 4.1. User's guide. Montreal, QC, Canada: Author.

Ryan, G. W., \& Bernard, H. R. (2000). Data management and analysis methods. In N. K. Denzin \& Y. S. Lincoln (Eds.), Handbook of qualitative research (pp. 769-802). Thousand Oaks, CA: Sage.

Sandelowski, M. (2008). Theoretical saturation. In L. M. Given (Ed.), The Sage encyclopedia of qualitative methods (Vol. 1, pp. 875-876). Thousand Oaks, CA: Sage.

Sandelowski, M., Voils, C. I., \& Knafl, G. (2009). On quantitizing. Journal of Mixed Methods Research, 3, 208-222. https://doi.org/10.1177/1558689809334210

Strauss, A., \& Corbin, J. (1998). Basics of qualitative research: Techniques and procedures for developing grounded theory. Thousand Oaks, CA: Sage.

Subramanyam, K. (1983). Bibliometric studies of research collaboration: A review. Journal of Information Science, 6, 33-38. https://doi.org/10.1177/016555158300600105

Tashakkori, A., \& Teddlie, C. (1998). Mixed methodology: Combining qualitative and 
quantitative approaches. Applied Social Research Methods Series (Vol. 46). Thousand Oaks, CA: Sage.

Teddlie, C., \& Yu, F. (2007). Mixed methods sampling: A typology with examples. Journal of Mixed Methods Research, 1, 77-100. https://doi.org/10.1177/2345678906292430

Vimala, B., \& Dominic, J. (2013). International Journal of Qualitative Methods (2002-2011): A bibliometric study. Asian Journal of Information Science and Technology, 3(2), 44-49.

\section{Copyright Disclaimer}

Copyright for this article is retained by the author(s), with first publication rights granted to the journal.

This is an open-access article distributed under the terms and conditions of the Creative Commons Attribution license (http://creativecommons.org/licenses/by/3.0/). 